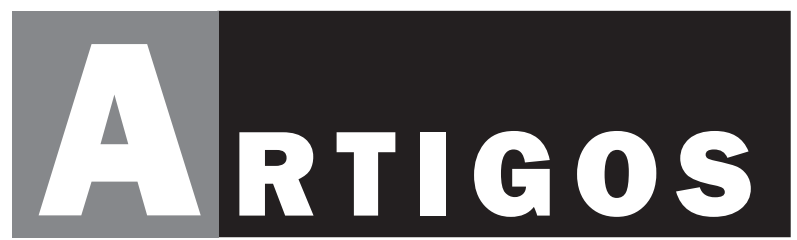




\title{
Refúgio e Família entre Mulheres do Conflito Sírio no Brasil e Tunísia ${ }^{1}$
}

\section{Refuge and Family among Women from the Syrian Conflict in Brazil and Tunisia}

\author{
Mirian Alves de Souza \\ Universidade Federal Fluminense, Niterói, Rio de Janeiro, Brasil
}

\section{RESUMO}

Este artigo tem o objetivo de oferecer alguns dados que possam enriquecer a produção antropológica no campo da migração forçada. A partir de uma etnografia com pessoas refugiadas do conflito sírio, o texto focaliza narrativas de mulheres no Brasil e Tunísia. A pesquisa adotou o método etnográfico, baseado em observação participante, no Rio de Janeiro, e entrevistas em Tunis e São Paulo. Existem poucos trabalhos nestes contextos com foco nas mulheres refugiadas do conflito sírio. Outra contribuição da pesquisa, no campo dos estudos sobre família e refúgio, é a apresentação de uma descrição das relações familiares anteriores e durante o deslocamento. Os dados da pesquisa, em consonância com a bibliografia, confrontam a afirmação de um colapso nas relações familiares no exílio.

Palavras-chave: Refúgio, Família, Conflito sírio, Mulheres.

1 A pesquisa foi financiada por meio de bolsa de doutor júnior da Fundação Casa de Rui Barbosa (FCRB), de setembro de 2015 a setembro de 2017, e com recursos de projetos da Fundação de Amparo à Pesquisa do Estado do Rio de Janeiro (FAPERJ). Agradeço aos pareceristas pela leitura atenciosa e considerações. 


\section{ABSTRACT}

The aim of this article is to offer some data that can enrich anthropological production about forced migration. Based on an ethnography of refugees from the Syrian conflict, the article focuses on women's narratives in Brazil and Tunisia. This research adopted the ethnographic method, based on participant observation, in Rio de Janeiro, and interviews conducted in Tunis and São Paulo. There are few academic works developed in these contexts that focus on women refugees from the Syrian conflict. Another contribution of the research, in the field of studies on family and refuge, is the presentation of a description regarding family relationship prior to and during displacement. The research data, in line with the bibliography, confront the affirmation of a collapse in family relationships in exile.

Keywords: Refuge, Family, Syrian conflict, Women.

\section{INTRODUÇÃO}

O refúgio como objeto antropológico tem sido problematizado, porque sob esta categorização se omite uma enorme variedade de situações do ponto de vista histórico, geográfico e cultural. A universalização de grupos deslocados na categoria "refugiado" tem produzido desistoricização e despolitização (MALKKI, 1995). Barbara Harrell-Bond (2002), em sua pesquisa com pessoas refugiadas de Uganda no Sul do Sudão, critica a incapacidade de trabalhadores humanitários, no cotidiano de suas ações, em reconhecer diferenças. Harrell-Bond (2002, p. 56) argumenta que "as populações de refugiados são heterogêneas de muitas maneiras (idade, educação, gênero, classe social e assim por diante), mas o método per capita de distribuição da ajuda é o 'nivelador', ele enfatiza sua 'igualdade' ou 'homogeneidade'”. Liisa Malkki (1995), a partir de sua pesquisa com refugiados hutus na Tanzânia, mostra que as organizações humanitárias reproduzem imagens e discursos padronizados sobre os refugiados, caracterizando-os como "meras vítimas" ou como "um tipo generalizado e idealizado".

Porém, não apenas no contexto de organizações humanitárias, como também no campo acadêmico (STEIN, 1981; KELLER, 1975), quase como uma "tribo" antropológica essencializada, os refugiados tornaram-se não apenas uma categoria mista de pessoas que compartilham um certo status legal; eles se tornaram "uma cultura", "uma identidade", "um mundo social” ou "uma comunidade". Há uma tendência, então, a proceder como se todos os refugiados compartilhassem uma mesma condição ou natureza comum (MALKKI, 1995, 1996). 
As pesquisas desenvolvidas por Barbara Harrell-Bond (1982, 2002) e Liisa Malkki $(1995,1996)$ representam uma produção crítica no campo da antropologia (por exemplo: FASSIN, 2010; AGIER, 2011; SCHIOCCHET, 2011; HAMID, 2012; NAVIA, 2014; URIARTE, 2018; LOKOT, 2018). Essa produção busca pensar o refúgio e a experiência do deslocamento considerando o conflito que produz a migração forçada, a dimensão política normativa do estado-nacional e os contextos históricos e sociais de origem, trânsito e destino das pessoas, assim como os seus diferentes pertencimentos culturais. Busca-se romper com uma narrativa homogênea sobre os refugiados, analisando a pluralidade de experiências no contexto do refúgio, as quais estão relacionadas a marcadores identitários diversos. Este artigo tem por objetivo oferecer alguns dados que possam enriquecer esta discussão, a partir da etnografia com refugiados do conflito sírio.

A literatura da antropologia sobre refugiados do conflito sírio tem dado atenção: aos laços familiares, culturais e linguísticos compartilhados com jordanianos (ACHILI, 2016); ao papel da classe social para a experiência do exílio entre mulheres sírias no Cairo, Egito (AYOUB, 2017); ao apoio prestado pelos palestinos aos refugiados sírios no campo de Chatila, no Líbano (SHARIF, 2018); às relações anteriores e durante o deslocamento dentro e fora das famílias sírias a partir da Jordânia (LOKOT, 2018); ao papel de organizações confessionais para o acesso à ajuda humanitária em São Paulo (MEIHY, 2019); e à questão da moradia para refugiados sírios e palestinos no Brasil (SOUZA; MANFRINATO, 2020).

Este artigo busca contribuir para essa produção, olhando em particular para as narrativas de três mulheres em dois contextos de Sul global, Brasil e Tunísia. Existem poucos trabalhos com foco em narrativas de mulheres, de maneira geral, e especialmente nestes contextos (ARAISSIA, 2019; ABDELLATIF, 2018). As histórias de Sila, Randa e Muna são articuladas, porque rompem com uma narrativa cristalizada sobre a família e mostram que nem sempre o deslocamento produz rupturas e perdas de vínculos familiares.

Os dados da pesquisa, em consonância com a bibliografia (LOKOT, 2018), confrontam a conclusão de um colapso nas relações familiares no exílio. Ao examinar como as redes sociais e o capital social contribuem para o bem-estar dos sírios em Irbid, Jordânia, Stevens considera que as redes sociais, que tradicionalmente forneciam apoio em tempos de dificuldades, entraram em colapso sob a penosa tensão financeira e social dos anos de deslocamento.

As redes sociais tradicionais não estão contribuindo para o suporte financeiro e emocional das famílias sírias em Irbid, na Jordânia, apesar da existência de familiares ou outras relações às quais se poderia pedir ajuda. Em vez disso, as redes sociais que tradicionalmente forneciam suporte em tempos de dificuldades ruíram sob a pressão financeira e social de anos de deslocamento 
(STEVENS, 2016, p. 52).

A conclusão do trabalho de Stevens expressa uma visão um tanto funcionalista, questionada por Liisa Malkki. Para Malkki, trabalhos desenvolvidos no campo dos "estudos sobre refugiados" (STEIN, 1981; KELLER, 1975) supõem que se desenraizar e se deslocar de uma comunidade nacional é necessariamente perder sua identidade, tradição e cultura (MALKKI, 1995, p. 508). No âmbito das organizações humanitárias essa visão é igualmente compartilhada. Relatórios de agências humanitárias (EL-MASRI; GARWOOD; HARVEY, 2013; UNHCR, 2014; BUECHER; ANIYAMUAALA, 2016) enfatizam o impacto do exílio na estrutura das comunidades sírias, apresentando as relações sociais como perpetuamente quebradas devido à guerra. Segundo o relatório "Woman Alone: Fight for survival by Syria’s Refugee Women”, "as famílias sírias são tradicionalmente muito unidas. A guerra mudou tudo isso, separando famílias e comunidades. Homens foram mortos, presos ou gravemente feridos. O medo, como uma constante, entrou em suas vidas". (UNHCR, 2014, p. 9)

O poder predominante da família no contexto do Oriente Médio tem sido reconhecido por diversos autores (JOSPEH, 1999; DAHLGREN, 2008; RABO, 2008). Nesta região, a identificação com a família e o grupo de parentes é a base da identidade de um indivíduo. E isso é verdade para ambos os sexos (EL GUINDI, 1999, p. 164). A família é vista como um "espaço sagrado" (JOSPEH, 1999, p. 9), mas os pesquisadores enfatizam que ela não é uma entidade estática.

Beshara Doumani, por exemplo, argumenta que é preciso contextualizar e historicizar a família. Esvaziada de substância histórica, ela é discutida em termos monolíticos e enquadrada monocromaticamente como tradicional ou moderna (DOUMANI, 2003, p. 3; 2017, p. 17). Este enquadramento se vincula a construções nacionais e culturais que modelam os imaginários sociais do Estado, "o qual privilegia determinadas concepções idealizadas na noção de 'família muçulmana'2. Os discursos nacionalistas colocaram a família no centro das visões políticas, que renegociam as relações sociais tradicionais em benefício do Estado" (DAHLGREN, 2008, p. 7).

No contexto da Síria, Lisa Wedeen argumenta (1999, p. 51) que o papel da família é tão difundido que metáforas de família operam na narrativa oficial para representar as relações

2 A produção antropológica contemporânea oferece visões e interpretações bastante nuançadas das disputas pela definição dos símbolos públicos e discursos morais e religiosos sobre a família e a mulher muçulmana (ABU-LUGHOD, 2013; MAHMOOD, 2005; RABO, 1996, 2008; CHAGAS, 2011). 
idealizadas de filiação e dominação do regime ${ }^{3}$ e para especificar a forma de obediência pública. A construção de uma família nacional pelo culto a Hafez Al Asad, o "pai nacional”, deriva sua coerência e inteligibilidade das relações reais entre os sexos e a compreensão prática, vivida de gênero e poder dentro das famílias sírias. Desde a "revolução" Ba'ath de 8 de março de $1963^{4}$, "a família" havia perdido cada vez mais as funções disciplinares e de cuidado para as instituições estatais emergentes, como o exército, fábricas, hospitais, escolas e prisões. A Guerra de 1967 teve o efeito de transferir funções adicionais anteriormente desempenhadas por famílias sírias para o estado (WEDEEN, 1999, p. 52).

Annika Rabo (1996) aborda o projeto modernizante do partido Ba'ath, o único a governar a Síria desde a década de 1960. Neste projeto, concepções de gênero consideradas "tradicionais" são condenadas como resquícios de uma ordem patriarcal que o partido se esforça para eliminar. Nessa retórica, os laços de parentesco são vistos como fomentadores de uma espécie de solidariedade que ameaça o progresso da sociedade. A organização de pessoas em clãs, tribos ou famílias numerosas é considerada "feudal" e uma ameaça para a nação. As iniciativas do "feminismo de estado sírio", como os grupos de estudos para mulheres adultas, organizados pelo Sindicato das Mulheres, controlado pelo Ba'ath, são instrumentos importantes para ensinar as mulheres a "se livrarem das atitudes tradicionais da família" (RABO, 1996, p. 160).

Uma referência final que serve de suporte para o meu campo etnográfico é a pesquisa de Michele Lokot (2016), que questiona conclusões sobre a experiência do refúgio e visões simplistas sobre a família, como as que estão presentes em discursos acadêmicos (STEVENS, 2016) e humanitários (EL-MASRI; GARWOOD; HARVEY, 2013; UNCHR, 2014; BUECHER; ANIYAMUAALA, 2016). Lokot explora como mulheres e homens sírios na Jordânia

3 A categoria regime designa o governo do atual presidente da Síria, Bashar al-Asad e se refere ao governo de seu pai, Hafez. Bashar al-Asad se tornou presidente da Síria depois da morte de seu pai, que presidiu o país de 1970 a 2000. Bashar al-Asad consolidou uma dinastia política no poder, chamada por seus oponentes de república de reis (jumlukiya) (PINTO, 2013, p. 211).

4 A efetiva construção do Estado-nação na Síria não começou até 1963, com o golpe que levou o Partido Ba'ath ao poder. O partido socialista panárabe (Hizb Al-Ba'ath Al-'Arabi Al-Ishtiraki) tem como objetivo abolir as instituições tradicionais, definidas como "feudal, tribal e patriarcal" (RABO, 1996, p. 153).

5 A construção do estado-nação na Síria é marcada por um discurso secular de combate a práticas consideradas tradicionais, como o uso do hijab (véu islâmico) no espaço público. A discussão sobre agência feminina tem sido explorada na literatura sobre mulheres muçulmanas. A etnografia de Saba Mahmood (2005) nas mesquitas do Cairo, em um movimento conservador de mulheres, deu lugar a uma nova concepção de agência. Mahmood desenvolveu um conceito de agência devota, que amplia a capacidade de compreensão das mulheres cujo sentido de self, aspirações, projetos e desejos, incluindo o de submissão a uma autoridade reconhecida, foram configurados no seio de tradições não liberais. Mahmood defende uma separação entre a noção de agência e a de resistência como um passo fundamental para se pensar as formas de vontade e política que não se adequam às normas seculares e liberais feministas (incluindo o "feminismo de estado"). 
desafiam e mantêm os laços familiares. Ela sugere que o poder da família em moldar as relações sociais e a diversidade de experiências entre os sírios precisam ser mais bem compreendidas por acadêmicos e por agências humanitárias e governos.

Os refugiados não podem ser descritos como se compartilhassem de uma mesma história de deslocamento e suas relações familiares não podem ser consideradas, inexoravelmente, rompidas por causa do deslocamento forçado. Lokot argumenta que as experiências de mulheres e homens no exílio variam em relação à geração, ideologia, classe social, lugar de origem e pertencimento étnico e religioso, entre outros fatores e circunstâncias.

Este artigo apresenta, primeiro, informações sobre o trabalho de campo antropológico realizado e números do conflito sírio; depois, as narrativas de três mulheres que mostram as complexidades da experiência do exílio e, por último, uma análise que confronta representações idealizadas da família e que desafia discursos simplistas em torno do refúgio. Propõe-se apresentar uma descrição mais complexa das relações no exílio, considerando a dinâmica familiar antes e durante a migração e os diferentes pertencimentos das mulheres.

\section{METODOLOGIA}

O trabalho de campo que informa este artigo foi conduzido em dois períodos. Primeiro, de outubro de 2015 a setembro de 2018, no Rio de Janeiro e em São Paulo, Brasil. Depois, ele foi desenvolvido, de março a julho de 2019, em Tunis, Tunísia. No Rio de Janeiro, a pesquisa adotou uma metodologia baseada na observação participante. O trabalho de campo foi desenvolvido com imersão, por meio do consumo regular de "comida síria", produzida e comercializada por alguns interlocutores, e por meio das aulas de árabe com professores refugiados.

A noção de reciprocidade, "dar alguma coisa em troca" (LIAMPUTTONG, 2007, p. 60) orientou a pesquisa, de modo que o trabalho de campo também foi marcado por minha colaboração para a abertura de conta bancária, acesso ao serviço público de saúde, educação, e assistência a organizações humanitárias e a informações e esclarecimentos sobre o processo de refúgio. Em contraste, para o trabalho de campo em São Paulo e Tunis me concentrei na realização de entrevistas mais estruturadas e observação direta. Contudo, mesmo nesses contextos, nos quais tive pouco convívio com os interlocutores, a presença de crianças pequenas, como minha filha, criava um ambiente mais informal e empático.

A etnografia que realizei privilegiou a descrição do processo de acolhimento de pessoas 
afetadas pelo conflito sírio em contextos nacionais nos quais meus interlocutores eram responsáveis por sua vida social e econômica. Isso significa dizer que não houve auxílio do estado brasileiro ou tunisiano para o deslocamento e eles não foram acolhidos por programas especiais para refugiados. A pesquisa envolveu cidadãos sírios e de outras nacionalidades, como palestinos e libaneses. Esses refugiados viviam em áreas urbanas do Rio de Janeiro, São Paulo e Tunis e tinham grande diversidade socioeconômica.

As pessoas que participaram da pesquisa tinham entre 18-65 anos e eram em sua maioria de Damasco, Alepo, Dayr al-Zor, Daraa, Raqqah e Homs na Síria. Participaram refugiados de outras nacionalidades, sem necessariamente relação com o conflito sírio, como marroquinos, egípcios, um sudanês e um líbio. Foram realizadas 20 entrevistas mais estruturadas, sendo atividades do dia a dia, como as aulas de língua árabe, momentos importantes para a construção de um conhecimento sobre a história de vida dos interlocutores no contexto de refúgio. As entrevistas e aulas particulares foram conduzidas em minha casa, na residência de algumas interlocutoras, em cafés, restaurantes e na Fundação Casa de Rui Barbosa. Feiras de comida, organizações humanitárias e confessionais, eventos culturais e acadêmicos, como palestras e peças teatrais também foram espaços para o desenvolvimento do trabalho de campo.

As entrevistas foram realizadas em inglês, mas o uso do árabe e do português era frequentemente acionado. Estudar a língua árabe durante o trabalho de campo contribuiu para gerar empatia, mostrar meu engajamento diante do tema, fazer anotações mais adequadas e problematizar conceitos. Em três entrevistas, contei com duas tradutoras durante todo o tempo e, em outras ocasiões, com a tradução de outros interlocutores presentes ou de aplicativos de celular.

\section{CONFLITO SÍRIO}

Desde o começo do conflito sírio, em 2011, estima-se que 6,7 milhões de pessoas foram deslocadas internamente na Síria, 5,6 milhões deixaram o país, e 13,5 milhões precisam de ajuda humanitária. A maioria dos refugiados está em países vizinhos, que fazem fronteira com a Síria, os quais abrigam $90 \%$ do total de deslocados. Os países que mais receberam refugiados sírios são Turquia, Líbano e Jordânia (ACNUR, 2018).

$\mathrm{Na}$ Tunísia, o Institut National de la Statistique divulgou que, em 2014, havia 1.024 refugiados sírios no país (BOUBAKRI, 2015, p. 26). Os números, contudo, deveriam ser bem 
superiores. Segundo Boubakri, o secretário de Estado para "Migração e Integração Social” da Tunísia estimava o número 4.000 sírios presentes no país, enquanto o escritório do ACNUR registrava 629 refugiados (BOUBAKRI, 2015, p. 32). Em 2019, Vincent Cochetel, representante do ACNUR na Tunísia, informou que 1.031 sírios pediram refúgio ou eram refugiados no país (GRASSO, 2019).

No Brasil, entre 2011 e 2018, 3.326 cidadãos sírios foram reconhecidos como refugiados, segundo dados oficiais do Comitê Nacional para refugiados (CONARE, 2019), que administra o refúgio no Brasil. A entrada de pessoas afetadas pelo conflito sírio foi facilitada, por razões humanitárias, por meio da flexibilização das exigências para a concessão de visto em embaixadas e consulados brasileiros.

Por intermédio da Resolução normativa 17 de 2013, com validade de dois anos, e renovada nos anos de 2015 e 2017, o CONARE orientou a emissão de vistos para pessoas afetadas pelo conflito sírio, considerando palestinos e cidadãos de outras nacionalidades que residiam na Síria ${ }^{6}$. A inclusão de nacionais de outros países na política de refúgio brasileira viabilizou o acesso à proteção a indivíduos que, embora afetados pela guerra, costumam ser excluídos de programas de proteção.

A Tunísia, por sua vez, ao cortar relações com o governo sírio em 2012, como um sinal de "solidariedade ao povo sírio em suas reivindicações por liberdade e dignidade" (TURESS, 2012), criou obstáculos para a entrada de sírios no país. Entre meus interlocutores, alguns foram forçados a transitar por via aérea através da Argélia e, depois entrar na Tunísia, irregularmente, através da fronteira terrestre?

\section{SILA, SAMIA E MUNA}

As narrativas de três interlocutoras permitem mostrar as complexidades da experiência do exílio. Sila, Samia e Muna enfrentaram grandes desafios em seus processos migratórios, as suas relações familiares e sociais foram marcadas por conflitos e desentendimentos, mas também por reconciliações e surpreendentes manifestações de afeto e solidariedade.

6 A Síria abrigava aproximadamente 500,000 refugiados palestinos, dos quais 149,822 viviam em um de seus nove campos oficiais (CASTELLINO; CAVANAUGH, 2013, p. 157).

7 A pesquisa de Hajer Araissia (2019) discute o impacto dessa decisão para a precarização das condições de deslocamento ao focar sua análise nas mulheres sírias refugiadas na Tunísia. 
Sila

Sila vivia em Damasco com sua mãe, onde nasceu na década de 1990. Seus pais se divorciaram quando ela era criança e, embora tenha morado com seu pai durante alguns anos, passou a maior parte de sua vida com sua mãe. Ela estudou em uma escola bilíngue em Damasco, motivo pelo qual fala inglês fluentemente, fazia aulas de pintura no Russian Cultural Center, e frequentava outros espaços sociais de classe média alta na Síria. A família de Sila era muçulmana sunita ${ }^{8}$, mas como seus pais não eram praticantes, ela nunca frequentou uma mesquita.

Antes do conflito, Sila já tinha planos de deixar a Síria. Ela me contou que passava bastante tempo pesquisando na internet em busca de um destino, que deveria ser internacional, com falantes de língua inglesa, e sobretudo com praias paradisíacas. As ilhas Cook, um país autônomo associado à Nova Zelândia, que tem o inglês como uma língua oficial, era um exemplo de destino idealizado.

Sila pensava em viver em outro país. Contudo, o fator decisivo para que deixasse a Síria, em 2015, foi o medo do barulho dos bombardeios que ela ouvia vindos do subúrbio de Damasco:

Eu já queria sair da Síria, mas pensava em estudar na Europa ou ir para as Ilhas Cook. Decidi deixar o país quando começamos a ouvir os bombardeios. As bombas não atingiam o meu bairro, mas o barulho vindo do subúrbio era muito alto e assustador (Entrevista em junho de 2016).

Diante dos bombardeios e a perspectiva de que o conflito se ampliasse, Sila começou a pesquisar destinos possíveis. Ela já sabia, nesse momento, que vários países começavam a fechar suas fronteiras para cidadãos sírios, incluindo o Líbano, onde passou três meses trabalhando em um bar de Beirute. Malásia e Equador estavam abertos e não exigiam sequer visto de entrada. Sila foi então para a Malásia, onde passou um mês. No país, no entanto, ela percebeu que não teria muitas perspectivas de trabalho e voltou para a Síria. A volta para Damasco foi motivada, ainda, pelo estado de saúde de sua mãe, que tinha descoberto um tumor. Sila passou nove meses em sua cidade acompanhando a mãe nas sessões de quimioterapia, radioterapia e consultas médicas. Durante esse período de volta à Síria, ela soube que o Brasil estava flexibilizando as exigências para a entrada de sírios no país. Embora tenha gostado dos meses que

8 As três interlocutoras cujas histórias são abordadas neste artigo eram muçulmanas sunitas e se identificavam etnicamente como árabes. A Síria, contudo, era marcada por uma enorme diversidade étnica e religiosa. Segundo dados de Edith Szanto, a população Síria consiste em 70\% de árabes sunitas, $15 \%$ de alauítas, 5\% de cristãos, 3\% de druzos, $1 \%$ de xiitas ismaelitas e $1 \%$ de xiitas duodecimanos. Curdos sunitas correspondem a $10 \%$ (SZANTO, 2013, p. 3). 
passou em Beirute com amigos que, como ela, haviam deixado a Síria, Sila considerava que o Líbano, assim como a Malásia, não eram destinos viáveis.

O Brasil aceitava sírios, concederia refúgio, e o Rio de Janeiro tinha características muito atrativas, especialmente por suas praias e paisagem natural. Antes de vir para o Brasil, Sila passou cinco meses trabalhando na Turquia com o objetivo de reunir recursos para a sua viagem. Em Istambul, ela providenciou seu visto no consulado brasileiro e organizou sua partida. Ela desembarcou em São Paulo, onde foi acolhida por um amigo brasileiro que conheceu pela internet, no website Meet up, em um grupo chamado "brasileiros que falam árabe".

Sila passou apenas cinco dias em São Paulo e, quando chegou ao Rio de Janeiro, ficou hospedada na casa de um amigo sírio, que também conheceu pela internet, na rede social Couch surfing, que oferece hospedagem gratuita. Sila passou duas semanas em sua casa, alugada por meio do website Airbnb. Depois disso, ela foi morar em um quarto compartilhado com outras mulheres em um hostel.

Alguns meses depois, Sila foi responsável pela vinda de sua mãe, que passou algumas semanas na casa de seus amigos na Turquia a fim de providenciar o seu visto para o Brasil. Sila acompanhava todos os passos de sua mãe por intermédio de seus amigos. O telefone celular comprado em Istambul garantia a comunicação. Com a chegada de sua mãe ao Brasil, Sila decide alugar um quarto exclusivo para mãe e filha, porque o quarto que dividia com outras pessoas não parecia mais adequado.

$\mathrm{Na}$ Síria, mãe e filha viviam da renda de um apartamento alugado que possuíam. O bairro desse imóvel, no entanto, foi fortemente atingindo por um bombardeio e a renda desse aluguel se perdeu. Elas ainda não sabem se o imóvel foi completamente ou parcialmente destruído, uma vez que a área está interditada. Além disso, elas contavam com o benefício de pensão de morte do pai de Sila. A pensão que recebiam na Síria não podia ser enviada ao Brasil e, se pudesse, não faria diferença, uma vez que a libra síria praticamente não tem valor fora do país.

Apesar dos desafios em viver em um país que não conta com um programa de assistência a refugiados, Sila gostava de viver no Brasil, onde conseguiu se fixar com o apoio da rede de relações de trabalho e amizade que construiu. Ela estudava em uma universidade pública no curso que sempre desejou e trabalhava como professora de inglês, sendo esta sua principal fonte de renda. Ela era muito próxima das coordenadoras do curso no qual trabalhava e com as quais mantinha uma forte relação de amizade: "Esse trabalho mudou a minha vida".

Um dos principais desafios da vida de Sila era sustentar sua mãe, uma mulher da elite damascena, que nunca trabalhou. Em sua juventude ela não precisava trabalhar, nasceu e cresceu no seio de uma família abastada, mas, mesmo com o divórcio e o declínio econômico familiar, 
ela não aceitou a ideia de fazê-lo quando se tornou necessário: "Minha mãe tem mentalidade de elite, mesmo precisando, ela se recusou a trabalhar" (Entrevista em maio de 2017).

A mãe de Sila se sentia muito frustrada diante das condições de sua decadência social, agravada pelo exílio. Sila poderia viver com jovens amigos, mas, sua mãe, uma senhora de quase setenta anos, saúde fragilizada, e com essa "mentalidade", demandava uma estrutura que exigia recursos que ela não conseguia adequadamente prover. O deslocamento derivado da migração forçada subverteu a relação entre gerações, transformando Sila, a filha, em provedora. Essa nova configuração familiar aumentou as tensões que marcavam a relação entre mãe e filha, mas o exílio não era visto por Sila como a razão dos problemas enfrentados: "A minha mãe sempre foi difícil de lidar, desde antes do conflito. Ela era assim na Síria. Ela reclama, nunca teve amigos. Mas agora eu me sinto muito mais responsável por ela. Ela é minha família. Sempre fomos eu e ela" (Entrevista em maio de 2017).

\section{Samia}

Samia nasceu em Damasco na década de 1980, em um campo não oficial de refugiados palestinos. Seus avós deixaram a Palestina em 1948 e se tornaram refugiados na Síria, em Golan. Com a ocupação israelense do território em 1982, eles foram para Homs e, depois, Damasco. Samia cresceu no subúrbio da cidade e estudou na Universidade de Damasco, onde conheceu seu marido.

Depois de três anos de casamento e com um filho pequeno, eles deixaram a Síria. Samia e Khaled chegaram ao Brasil em 2015. Dois anos depois, Samia decidiu fazer terapia. Ela conheceu sua psicóloga por intermédio de uma outra psicóloga, que trabalhava voluntariamente em uma mesquita em São Paulo. Para Samia, a relação com seus pais foi decisiva para que começasse a fazer terapia. Mesmo distante geograficamente, ela me disse que eles eram muito presentes: "Eu falo com eles quase todo o dia. Falar com eles é difícil, mas também é bom porque eu estou sempre preocupada, eles já se mudaram três vezes fugindo" (Entrevista em janeiro de 2017).

Para Samia, a distância de sua família suscitou uma reflexão sobre as relações familiares, que ela admitiu ter começado na Síria, mas abandonou porque estava sempre muito ocupada. No exílio ela encontrou um "tempo", que nunca dispusera na Síria, para fazer terapia, refletir sobre seu nafs (self):

Quando Nuri [seu filho] foi para a escola eu comecei a fazer terapia. Eu precisava falar sobre meus pais. Eu tenho uma baixa autoestima [...]. Mas olha a minha história. Eu quis fazer faculdade e tive que juntar dinheiro sozinha, ninguém quis me ajudar. Eu estudava de manhã, trabalhava à tarde e de noite. 
Os meus pais me davam muito mais trabalho quando comecei a estudar. Só tinha tempo para estudar de madrugada. E ainda consegui um jeito de estudar inglês. Escutava as fitas enquanto trabalhava e eles não gostavam (Entrevista em janeiro de 2017).

Samia disse que a partir da terapia começou a pensar sua trajetória de forma mais positiva, realçando suas conquistas em condições bastante adversas. Ela passou a refletir e compreender o impacto de sua decisão em não aceitar se casar com quem seus pais queriam: "Eu já fazia universidade e meus pais queriam que eu me casasse com um ajudante de mecânico, que era da família. Minha mãe o apoiava e achava que ele estava muito bom”. (Entrevista em janeiro de 2017). Samia quase se casou com o primo de seu pai e reconheceu que a decisão de os questionar, não aceitando o casamento, marcou a sua relação com seus pais definitivamente. Essa decisão ainda criou problemas com sua irmã mais nova, que apenas poderia se casar depois dela. Quando conheceu seu marido na Universidade de Damasco, ela decidiu rapidamente pelo casamento:

Na Síria a gente não namora, a gente casa. Mas na universidade tem gente que namora escondido. Mas assim que eu conheci o Khaled, falei para ele que teríamos que nos casar, que não aceitaria namorar e não podia esperar. E ele aceitou se casar. Eu não esperava, até porque na Síria, quem escolhe a esposa é a mãe do marido (Entrevista em janeiro de 2017).

Samia disse que não fez nenhuma exigência para o casamento, realizado poucos meses depois do pedido formal para sua família, de modo a não atrapalhar os planos de matrimônio da irmã. Samia realçou que as pessoas pensam muito em termos de religião ao abordarem as relações sociais na Síria, mas, no país, a classe social é muito importante. Ela nunca pensou em se casar com alguém como seu marido, ainda que tivesse rejeitado o ajudante de mecânico, que contava com a aprovação de seus pais.

A sua formação universitária, sucesso profissional, e casamento com um homem de família muçulmana sunita, como a dela, não impediam que os pais de Samia a criticasse. Em um de nossos encontros, quando cheguei à casa dela, ela me contou que tinha acabado de passar duas horas ouvindo sua mãe reclamar que ela só tinha um filho, enquanto seus irmãos, mesmo vivendo no contexto de uma guerra, tinham três filhos. A forma como ela criava seu filho e cuidava da casa também era objeto de críticas, ainda que à distância.

Os pais igualmente criticavam sua opção pelo Brasil: "Eles criticam porque sabem que fui eu que escolhi vir para o Brasil e não por ser um país não muçulmano (Dar al-Kufr)". Samia atribuiu sua escolha pelo Brasil à segurança em relação ao visto e ao pedido de refúgio. Ela 
tinha informações de que embaixadas e consulados brasileiros davam visto e que o pedido de refúgio no país encontraria aceitação. A primeira opção para a sua família era emigrar para um país do Norte global. Eles tentaram, mas não conseguiram.

No dia em que seu marido chegou em casa com a notícia de mais um visto negado, ela sugeriu a viagem para o Brasil e se tornou a principal responsável pela organização da viagem. Por intermédio de seus pais, Samia soube que membros de sua família e amigos, que estavam no Líbano, tinham conseguido visto para o Brasil. Ela ligou para uma prima, que embora tenha conseguido o visto brasileiro, optou em tentar, mais uma vez, viajar para a Europa. Essa prima, no entanto, colocou-a em contato com outro familiar, que já estava no Brasil. O primo, que vivia em São Paulo, contou sobre a comunidade árabe brasileira, as mesquitas em São Paulo, as oportunidades de trabalho que a cidade oferecia e sua complexa rede de metrô.

Diante da alta qualificação do casal, decidiram viver no Rio de Janeiro onde, em face da visibilidade da Copa do Mundo (2014) e Jogos Olímpicos (2016), teriam maiores chances de emprego. Ficaram, no entanto, apenas oito meses na cidade. Por meio de contatos de sua família, Khaled conseguiu uma posição de trabalho em São Paulo, para onde se mudaram. Quando chegaram à cidade, eles estavam muito abatidos. Durante sua estadia no Rio de Janeiro, eles tiveram despesas inesperadas e, além disso, não conseguiram acessar o dinheiro enviado pelo pai de Khaled, precarizando sua situação na nova cidade.

Nesse contexto, um grande incômodo para Samia foi a proximidade com seu primo e conhecidos de sua família: “Tem pessoas que estão com medo dos espiões de Asad, eu tenho medo da fofoca da família, que adora falar sobre as misérias da vida alheia" (Entrevista em março de 2017). Samia procurou se manter afastada de seu primo e conhecidos de sua família para evitar que eles divulgassem informações sobre as condições em que se encontravam.

A rede de apoio que Samia construiu no exílio, embora inicialmente contatada por meio de seu primo, caracterizava-se por pessoas sem laços com sua família. Essa rede de apoio foi descrita como muito melhor do que a que ela contava na Síria, formada por famílias de brasileiros e estrangeiros que ela e seu marido conheceram, sobretudo, na Mesquita em São Paulo. De acordo com Samia, na Síria, ela não contava com o apoio da família:

Eu fiz um bom casamento, mas eu quis casar o mais rápido que podia por causa da minha irmã. Quando eu precisei dela, quando estava com oito meses de gravidez, ela não me ajudou e minha mãe estava sempre ocupada [...]. Eu não podia esperar nada delas. Minha irmã só pensa nela. Se eu me recuso a ajudá-la, minha mãe me chama de egoísta e fala que toda família (aqarib) tem escorpiões (aaqarab) (Entrevista em janeiro de 2017). 
Samia não contava com o apoio da família de seu marido e sofria forte rejeição dela por sua origem social. "Eles nunca me aceitaram. Nosso casamento foi praticamente sem celebração. [...] A minha sogra, cunhadas e co-cunhadas pareciam estar sempre conspirando. Aaqarab [risos]" (Entrevista em março de 2017). Depois do conflito, Samia considerava que a família do marido passou a se relacionar com ela de forma muito diferente, conectando-se a ela, que disse conversar com eles com muito mais densidade e amorosidade.

Quando viviam na Síria, a relação com a família do marido era marcada, sobretudo, pelo controle social exercido por seus membros, que estavam frequentemente preocupados em impedir o seu contato com homens, restringindo sua circulação a espaços sociais exclusivamente femininos.

A situação de exílio contribuiu para uma inesperada aproximação entre Samia e a família de seu marido. Samia considera que, com o conflito, as relações de certa forma se horizontalizaram. Eles começaram a se conectar uns com os outros. A migração forçada por causa do conflito sírio criou denominadores comuns, pois estão quase todos fora do país, sendo ajudados pelos pais de Khaled, e compartilhando os mesmos desafios, como lidar com os papéis da migração ou refúgio, conhecer novas pessoas e adaptar as crianças a uma nova escola e cultura.

\section{Muna}

Para Muna, o deslocamento também a conectou com a família do marido, Aziz. Ela vivia em Daraa, onde nasceu na década de 1970, e nunca tinha pensado em deixar sua cidade. Ela se casou com seu marido, que morava no mesmo bairro e cuja família, como a dela, frequentava a mesquita local, e com ele teve três filhos. Em 2012, eles foram viver em Amã, na Jordânia, com a família do irmão de Muna, para onde depois foram igualmente outros membros da família.

Segundo Muna, sobretudo a família de seu marido foi muito afetada pelo conflito. Eles trabalhavam quase todos juntos e suas posições profissionais "se perderam". Os mais importantes foram para Damasco e os demais deixaram a cidade e empobreceram rapidamente. Apesar disso, eles se tornaram muito mais atenciosos, solícitos e disponíveis. Muna conta que se surpreendeu com o apoio financeiro recebido de membros da família do marido, ainda que estivessem passando por uma difícil situação econômica. Antes do conflito, Muna teve péssimas experiências com a família de Aziz: “a família pode ser perigosa”. Mas, no exílio, ela dizia que eles tinham se transformado:

Tudo mudou, o conflito mudou tudo. Eles eram muito difíceis, mas se abriram. Eles viviam entre eles, bem fechados, trabalhavam juntos e se você não trabalhasse com eles, não se relacionavam. Eu não me envolvia e o Aziz acabou ficando mais próximo da minha família. Ele sente muita falta da minha 
família, até mesmo mais dos meus irmãos (Entrevista em maio de 2019).

Na Jordânia, ela passou a conviver cotidianamente com a família de Aziz. Eles estavam muito mais presentes em suas vidas em Amã do que em Daraa. As cunhadas iam à sua casa regularmente para saber se ela queria receber roupas usadas, "mas de qualidade", brinquedos para seu filho mais novo e sobrinhos, filhos de seus irmãos. Eles também os visitavam para informá-los sobre os lugares de assistência social e humanitária e oportunidades de trabalho e estudo. Ela disse que a família do marido passou a se preocupar com eles de uma forma sem precedentes.

Depois de alguns meses em Amã, Muna passou a viver na casa de sua irmã cujo aluguel era pago por um de seus irmãos, empregado em um país do Golfo. Em Amã, na casa dessa irmã, da qual era muito próxima e com quem tinha uma boa relação, ela não encontrou a mesma solidariedade de outros familiares. Muna achava que a relação com sua irmã se modificou por causa do rebaixamento social de seu marido, que não conseguiu se empregar durante todo o tempo em que viveram na Jordânia.

A relação se tornava cada dia mais insuportável, com os comentários da irmã sobre a falta de dinheiro do cunhado e sua presença constante dentro de casa, até que Muna decidiu deixar a Jordânia em direção à Tunísia. A mãe de Muna, já falecida, era tunisiana. Seus avôs emigraram para Irbid, Jordânia, e, depois, sua mãe se casou com seu pai, cuja família era de origem síria. Entretanto, Muna não migrou para a cidade de sua família materna, que fica há quase $400 \mathrm{~km}$ de Tunis, onde a conheci.

A família escolheu Tunis em razão de um vizinho de Daraa, um trabalhador técnico especializado, que ofereceu trabalho ao marido de Muna, enquanto estavam na Jordânia. Aziz hesitou em aceitar a proposta de emprego, mas Muna encorajou seu marido, porque estava decidida a deixar Amã. Esse vizinho tinha um forte vínculo de amizade com ela e sua família materna e foi por intermédio dele que conheceram a pequena comunidade síria em Tunis. Essa comunidade reunia jordanianos, sendo famílias dessa nacionalidade, e mais especificamente de Irbid, com as quais Muna passou a se relacionar.

Culturalmente próximos e politicamente distantes do conflito sírio, as famílias jordanianas se tornaram amigos estratégicos para que Muna se relacionasse com a comunidade síria, mas sem muita intimidade, limitando os laços de amizade aos jordanianos de Irbid: "Com outros sírios, a gente tem que ter atenção [...]. Os jordanianos de Irdib são muito próximos, é a mesma comida, a mesma cultura de Daraa" (Entrevista em maio de 2019).

Muna contou que, por ser filha de comerciantes, ela sempre se relacionou com pessoas de fora do seu círculo familiar, como o vizinho e sua família, responsáveis por terem decidido 
viver em Tunis. Por outro lado, Aziz tinha uma vida social bem mais restrita, relacionando-se exclusivamente com sua família e, depois de casado, com a família de sua mulher. Muna realçou como o seu marido era amigo de seus irmãos, primos e cunhados, com os quais sempre jogava cartas e frequentava os cafés tanto na Síria quanto na Jordânia. Ela contou que, em Tunis, foi a primeira vez que o marido fez amizades fora do círculo familiar. Diferentemente dela, a relação de seu marido com vizinhos, por exemplo, era muito formal. Ela visitava e era visitada por suas vizinhas regularmente, mas ele nunca fazia o mesmo. Amigos apenas parentes.

Quando Aziz perdeu o emprego em Tunis, a opção encontrada pelo casal para se sustentar na cidade foi abrir um pequeno comércio. Para a abertura do negócio, eles contaram, mais uma vez, com uma importante contribuição financeira da família de seu marido. Muna contou que a comunidade religiosa da mesquita que passaram a frequentar teve um papel importante para que decidissem permanecer no país, apesar dos problemas financeiros.

Pessoas da comunidade auxiliaram para seu entendimento em relação ao processo burocrático de migração e, sobretudo, tornaram-se os principais consumidores do estabelecimento aberto pelo casal. Com o comércio, a vida social de Muna se tornou muito mais restrita. Ela não tinha tempo para as visitas que costumava fazer e se relacionava quase que exclusivamente com as mulheres da mesquita apenas nas sextas-feiras, dia de oração. No negócio, ela estava sempre nos bastidores. Embora Muna descrevesse sua vida em Tunis como muito mais restrita socialmente, ela não pensava em deixar o país sem um plano viável de retorno para Daraa.

Além da proposta de trabalho recebida pelo marido, Muna disse que sua decisão em viver em Tunis tinha também a ver com um sonho que se repetiu por duas vezes enquanto estavam em Amã: “Toda a família estava reunida e entrávamos na mesquita de Zaituna. Só que os meus filhos eram crianças. No sonho, todos eram crianças" (Entrevista em maio de 2019).

Ela contou que, quando visitou a mesquita de Zaituna, em Tunis, teve certeza de que se tratava da mesquita de seu sonho. Para ela, o sonho foi uma mensagem de Deus para que se mantivesse em um país muçulmano (Dar al-Islam), lugar adequado para criar seus filhos, sobrinhos e sua descendência. Muna me falou sobre esse sonho, motivo pelo qual ela estava empenhada em trazer para Tunis uma de suas cunhadas cujo marido vivia na Europa.

Muna contou que não tinha uma boa relação com a cunhada. Considerava-a esnobe porque, anteriormente ao conflito, seu marido tinha uma posição de trabalho relevante em Daraa. Contudo, o empobrecimento da família também a teria transformado. Além disso, Muna se preocupava com os três sobrinhos, crianças iletradas e que deveriam receber sua ajuda: "Eu não gostava dela, mas agora vejo que ela sempre foi uma boa mãe, uma boa muçulmana, muito religiosa. Ela vai ficar feliz aqui, onde pode criar seus filhos." (Entrevista em junho de 2019). 
Para Muna, o exílio pode ser pensado como forma divina para que as relações familiares se transformassem e harmonizassem.

\section{REFÚGIO E RELAÇÕES FAMILIARES}

A experiência do exílio era muito diferente para Sila e sua mãe. Sila era jovem, estudava no curso universitário que sempre sonhou e tinha um trabalho do qual gostava e no qual fazia muitos amigos. Najma, sua mãe, tinha quase setenta anos, uma saúde fragilizada, e era descrita pela filha como uma pessoa amargurada diante de sua decadência social, mesmo antes do conflito na Síria. As diferenças entre as gerações devem ser consideradas, assim como os planos e perspectivas para a vida e interesse em permanecer e estabelecer relações no país de refúgio.

Enquanto viviam na Jordânia, Muna e Aziz achavam que iam voltar em breve para a Síria. Isso tinha implicações para que Aziz não se esforçasse em construir relações fora de sua família, ficando a maior parte do tempo em casa. Em Tunis, Aziz mudou o seu comportamento, não apenas por não ter família na cidade, mas porque os planos de permanência prolongada começaram a se desenhar. Muna pretendia inclusive levar os sobrinhos e parte da família para o país.

Ager e Strang argumentam que se os refugiados não tiverem a intenção de permanecer, eles não se esforçam para se "integrarem" (2008 p. 600). Um plano de permanência não é uma condição para a construção de relações sociais no exílio. Samia não pretendia viver no Brasil por muito tempo. Ela e seu marido estavam empenhados em viver em um país do Norte global, porém isso não os impediu de construírem e ampliarem sua rede de relações em São Paulo. Deve-se contextualizar que Samia sempre precisou do apoio de pessoas de fora da família. Ela contava com o suporte financeiro do pai de Khaled, mas aqui me refiro a afeto e apoio emocional, um sentimento mais profundo de cuidado e "conectividade" (JOSEPH, 1994, p. 55).

Samia interpretava a ausência de apoio como o preço a pagar por sua decisão de não respeitar os seus pais, recusando-se a casar com quem eles queriam e por se casar com alguém de uma outra classe social. Diante disso, Samia sempre investiu nas relações de amizade fora do círculo familiar.

A Síria é um país com uma enorme complexidade e variação em sua composição familiar, de modo que as pessoas não fazem nem falam da família da mesma maneira (RABO 2008, p. 131). Para Sila, sua família (aila) era constituída por ela e sua mãe. Seus irmãos, tios e 
tias e demais parentes eram classificados como a família (aqareb) da mãe ou do pai. O marido de Muna, Aziz, considerava os irmãos de sua mulher como parte de sua família, embora concordasse que, idealmente, eles não deveriam ser definidos como tal. Ele se sentia como parte da 'ashiire dos cunhados, categoria que expressa um sentido de família estendida, tipicamente associada à Síria rural e tribal (RABO, 2008, p. 132). A família de Khaled era definida com uma extensão bem diferente da família de Samia, ambos sunitas, mas de classes sociais e origens nacionais distintas. Muna e Aziz eram independentes economicamente de suas famílias, da província rural de Daraa, e a ajuda financeira recebida era justificada pela situação extraordinária produzida pelo conflito. Para Khaled, por sua vez, o dinheiro enviado por sua família, urbana e elitizada, no contexto do exílio não se configurava como uma "ajuda". Antes do conflito, Khaled já recebia regularmente dinheiro de seu pai, além do salário pago por ser empregado na empresa familiar.

Apesar de diferenças tão profundas na abordagem do que é uma família na Síria, há uma compreensão e aceitação geral de certos ideais. Os pais devem fazer todo o possível por seus filhos e, por sua vez, os filhos devem respeitar e venerar seus pais. Os membros da família e parentes devem ajudar e apoiar um ao outro, e quanto mais próximo o vínculo maiores expectativas de ajuda e apoio (RABO, 2008, p. 131).

Idealmente os familiares devem se apoiar. Contudo, isso não é o que se observa em todas as famílias, antes ou depois do deslocamento. Samia reclamou que não contava com o apoio de sua mãe e irmã, mesmo antes do conflito. Muna sofreu com as brigas com sua irmã durante o período em que viveram juntas em Amã e não se sentia conectada à família de seu marido, antes do deslocamento. Sila afirmava que se sua mãe voltasse para a Síria, não encontraria acolhimento por parte de suas irmãs, irmãos ou demais parentes em Damasco.

Amalia Sa’ar enfatiza uma distinção entre a ideologia da família como solidária, empática e afetuosa e a experiência da família, que para as mulheres muitas vezes é solitária, isolante e às vezes ameaçadora. Para elas, "a família como ideologia é significativamente separada da família como experiência" (SA'AR, 2001, p. 723). Em sua pesquisa com mulheres palestinas, Sa'ar apresenta exemplos impressionantes de mães e irmãs que não apenas deixam de apoiar suas filhas e irmãs em tempos de angústia, mas que se tornam hostis em face dos seus momentos mais solitários (SA'AR, 2001).

Interlocutores mencionaram o distanciamento de suas famílias em razão de suas posições ideológicas diante do conflito na Síria. Uma interlocutora mantinha-se distante de determinados membros da família do marido por eles apoiarem o regime de Bashar al-Asad e cooperarem ativamente para as forças de segurança do estado sírio. Paulo Hilu Pinto analisa como a própria 
família e comunidade religiosa silenciam seus membros quando têm posições dissonantes:

O regime usou seu aparato de segurança para mobilizar mecanismos repressivos internos sob a ameaça de que toda a comunidade sofreria sanções caso certos indivíduos não fossem suprimidos. Os manifestantes alauítas, cristãos e drusos enfrentaram repressão e violência dentro de suas próprias famílias (PINTO, 2017, p. 136).

Nesse sentido, a distância em relação a membros da família não pode ser explicada considerando exclusivamente o argumento de que o empobrecimento perturba as relações familiares, levando ao isolamento social e ao colapso das relações sociais (STEVENS, 2016, p. 56).

A etnografia Alfadhli e Drury também permite questionar a ideia de colapso das relações sociais entre refugiados, seja dentro ou fora de suas famílias. Eles argumentam que encontraram muitos exemplos de apoio entre os refugiados, tanto no nível pessoal quanto no coletivo. Parte desse apoio foi baseado no compartilhamento da identidade de "refugiado" que surgiu de um senso de destino comum, além de redes interpessoais pré-existentes (ALFADHLI; DRURY, 2018). A pesquisa de Meihy com famílias sírias na cidade de São Paulo mostrou a construção de uma rede de apoio entre os sírios, definida pelo pertencimento a determinadas confissões religiosas, que garantiram o acesso à ajuda humanitária (MEIHY, 2019).

A dinâmica das relações de gênero permite desafiar esse tipo de explicação, que se concentra no empobrecimento das famílias. Antes do exílio, Muna e sua irmã eram muito próximas. Contudo, ao viverem juntas na mesma casa em Amã, elas começaram a enfrentar uma série de desentendimentos que fortaleceram a decisão de Muna em deixar a Jordânia rumo à Tunísia. Os conflitos eram interpretados por Muna como em razão do desemprego do marido. Aziz era um homem que estava sempre em casa (beituti) e isso limitava a circulação de Sana no espaço doméstico. A irmã de Muna, uma jovem solteira, incomodava-se com a presença do cunhado em casa e das visitas de seus irmãos, que intensificavam a sua segregação.

Shampa Mazumdar e Sanjoy Mazumdar mostram como mulheres muçulmanas devem deixar certas partes de sua casa quando um homem com quem o casamento é possível a está visitando, explorando a complexidade de visões sobre "público e privado" em contextos islâmicos. Diante da presença de um não mahram ${ }^{9}$, o espaço privado se torna público, exigindo da mulher o uso do véu islâmico (hijab) e/ou distância social (MAZUMDAR; MAZUMDAR, 2001, p. 304). A literatura sobre a dinâmica de gênero das relações no contexto do Oriente Mé-

9 Mahram é uma categoria que designa pessoas com as quais o casamento é proibido. É importante dizer que nem todas as interlocutoras muçulmanas consideravam essa regra de distância social e usavam hijab. 
dio fornece análises interessantes, que mostram como as mulheres experimentam mais liberdade quando os homens não estão presentes (ABU-LUGHOD, 1985, p. 644).

A pesquisa indica que é um erro considerar que o deslocamento necessariamente intensifica a segregação das mulheres, assim como a ideia de que as mulheres de áreas rurais ou de classes sociais mais populares são mais segregadas do que as mulheres urbanas e elitizadas. Muna reclamou de como o seu círculo de relações se limitou no exílio, especialmente em Tunis. A experiência do refúgio limitou o seu contato com homens de uma forma que ela não vivenciava em Daraa.

Para Samia, o exílio ampliou a sua rede de relações, bastante restringida e controlada depois do casamento. Samia realçou a diferença entre o controle de sua família, que vivia no subúrbio de Damasco, e da família de seu marido, membro da elite damascena. Para Samia, as mulheres solteiras eram muito controladas em sua família, mas, depois do casamento, e especialmente com o nascimento dos filhos, esse controle era quase inexistente. A família elitizada de seu marido tinha uma concepção muito mais restrita dos espaços sociais em relação aos quais as mulheres poderiam circular.

Annika Rabo argumenta que regras sobre interação entre homens e mulheres podem ser menos rigorosas nas áreas rurais (RABO, 2008, p. 134). As mulheres de elite em Damasco encontram oportunidades, ainda que mais limitadas de interação, como os espaços semipúblicos das academias de ginástica. O contato físico era possível desde que ocorresse discretamente (SALAMANDRA, 2006, p. 154-5).

A classe social, assim como o valor atribuído ao trabalho (SALAMANDRA, 2004), tem um papel importante no que se refere ao exercício de uma atividade remunerada. No exílio, Samia trabalhava com a tradução de textos e atuava como secretária de seu marido, gerando uma renda complementar importante para a economia da família. Se não fosse o conflito, ela disse que estaria, certamente, dedicando-se a algum curso de pós-graduação, dividindo seu tempo entre sua formação e cuidados com a família. Para Samia, em Damasco não havia perspectiva de trabalho, mas em um país do Norte global, como o Canadá, ela poderia construir uma carreira. Ela se dizia diferente das mulheres da família de seu marido, que quando faziam universidade ou trabalhavam, era apenas como uma forma de atrair maridos.

Christa Salamandra (2004, p. 52) argumenta que a maioria dos empregos abertos às mulheres em Damasco, por mais prestigiado que seja, não paga o suficiente para permitir que as mulheres se tornem economicamente autossuficientes. Os empregos são vistos como medidas temporárias no caminho para o casamento ou posteriormente como renda suplementar. Para as jovens solteiras, os empregos são principalmente um local de exibição, cujo objetivo final é 
garantir um futuro de sucesso na esfera privada, e não na pública.

Muna não era uma mulher da elite. Ela trabalhava e não era por causa da migração forçada. Em Daraa, ela trabalhava, antes e depois do casamento, em uma rede de pequeno comércio administrado por seus pais e irmãos. Enquanto viveram na Jordânia, os serviços prestados por ela foram decisivos para a reprodução econômica da família, o que se manteve na Tunísia.

Sila trabalhou como operadora de telemarketing, atendente de bar e professora de inglês e árabe. Com o dinheiro de seu trabalho, ela sustentava sua família no Brasil. Embora tenha recebido episodicamente ajuda financeira de uma tia que vivia nos Emirados Árabes, o sustento familiar dependia exclusivamente de seu trabalho. A mãe de Sila nunca trabalhou, mas isso é interpretado por ela por causa de sua "mentalidade de elite".

\section{CONSIDERAÇÕES FINAIS}

Os dados apresentados mostram o poder da família. Na Síria contemporânea, a família é uma instituição central na organização da vida social. Em termos materiais, as conexões de parentesco funcionam para mobilizar pessoas e recursos; no nível simbólico, o parentesco evoca conexões íntimas (WEDEEN, 1999, p. 51).

Este artigo desafia a ideia de um colapso das relações familiares no refúgio, ao considerar as relações antes e durante o deslocamento. A descrição das relações familiares mostra que elas são complexas e imprevisíveis, exigem-se análises mais cuidadosas sobre o impacto do refúgio na estrutura das famílias.

Ao confrontar modelos idealizados de família e contextualizar diversos pertencimentos, este texto pretende contribuir para uma visão mais plural das relações familiares no contexto da migração forçada. Os refugiados não podem ser descritos como se compartilhassem de uma mesma história de deslocamento. As experiências de mulheres e homens no exílio variam em relação à geração, ideologia, classe social, lugar de origem e pertencimento étnico e religioso, entre outros fatores e circunstâncias.

O foco na diversidade e complexidade da experiência humana e a análise de múltiplas hierarquias de poder, que se cruzam e que moldam a vida das pessoas, desafiam explicações simplistas. 


\section{REFERÊNCIAS}

1. ABDELLATIF, S. Syrian Women Migrants in Tunisia: The Experience of Forced Migration and the Difficulty of Settling Down. Omran, vol 6, p. 51-69, 2018.

2. ABU-LUGHOD, L. A Community of Secrets: the Separate World of Bedouin Women. Signs, v. 10, n. 4, p. 637-57, 1985.

3. ABU-LUGHOD, L. Do Muslim Women Need Saving? Cambridge and London: Harvard University Press, 2013.

4. ACHILLI, L. Back to Syria? Conflicting Patterns of Mobility among Syrian Refugees in Jordan. Orient, v. 57, n. 1, p. 7-13, 2016.

5. ACNUR. Global Trends, Forced Displacement in 2018. 2018. Disponível em: https:// www.unhcr.org/5d08d7ee.pdf. Acesso em: 10 jan. 2020.

6. AGER, A.; STRANG, A. Understanding Integration: a Conceptual Framework. Journal of Refugee Studies, v. 21, n. 2, p. 166-91, 2008.

7. AGIER, M. Managing the Undesirables: Refugee Camps and Humanitarian Government. David Fernbach, Cambridge, UK: Polity, 2011.

8. ALFADHLI, K.; DRURY, J. The Role of Shared Social Identity in Mutual Support among Refugees of Conflict: an Ethnographic Study of Syrian Refugees in Jordan. Journal of Community \& Applied Social Psychology, v. 28, n. 3, p. 142-55, 2018.

9. AYOUB, M. Gender, Social Class and Exile: the Case of Syrian Women in Cairo. In: FREEMAN, J.; KIVILCIM, Z.; BAKLACIOĞLU, N. O. (org.). A Gendered Approach to the Syrian Refugee Crisis. Abingdon/New York: Routledge, 2017. p. 77-104.

10. ARAISSIA, H. Syrian Women Refugee in Tunisia: Difficulties Accessing Economic and Social Rights. Collectivus, Revista de Ciencias Sociales, v. 6, n. 2, p. 91-103, 2019.

11. BOUBAKRI, H. Migration et Asile en Tunisie Depuis 2011: Vers de Nouvelles Figures Migratoires? Revue Européenne des Migrations Internationales, v. 31, n. 3/4, p. 17 39, 2015.

12. BUECHER, B.; ANIYAMUZAALA, J. Women, Work and War: Syrian Women and the Struggle to Survive Five Years of Conflict. [S.l.: s.n.], 2016. Disponível em: https:// insights.careinternational.org.uk/media/k2/attachments/CARE_Syria-women-workand-war-report_2016.pdf. Acesso em: 15 fev. 2020.

13. CAStellino, J.; CAVANAUGH, K. Minority Rights in the Middle East. [S.l.]: Oxford Press, 2013. 
14. CHARRAD, M. M. States and Women's Rights. The Making of Postcolonial Tunisia, Algeria, and Morocco. Berkeley: University of California Press, 2001.

15. CONARE. Refúgio em números. 4. ed. [Brasília, DF]: [s.n.], 2019. Disponível em: https:/www.acnur.org/portugues/wp-content/uploads/2019/07/Refugio-emnu\%CC\%81meros_versa\%CC\%83o-23-de-julho-002.pdf. Acesso em: 20 fev. 2020.

16. DAHLGREN, S. Introduction: the Middle Eastern Family Revisited. Hawwa, v. 6, n. 1, p. 1-11, 2008.

17. DOUMANI, B. Family Life in the Ottoman Mediterranean: a Social History. Cambridge: University Press, 2017.

18. DOUMANI, B. Introduction. In: DOUMANI, Beshara (org.). Family History in the Middle East. Household, property, and gender. Albany: State University of New York Press, 2003. p. 1-19.

19. CHAGAS, G. F. Sufismo, carisma e moralidade: uma etnografia do ramo feminino da tariqa Naqshbandiyya-Kuftariyya em Damasco, Síria. 268 f. Tese (Doutorado em Antropologia) — Universidade Federal Fluminense, Niterói, RJ, 2011.

20. GRABSKA, K. Gender, Home \& Identity: Nuer Repatriation to Southern Sudan. Woodbridge, Suffolk: James Currey, 2014.

21. GRASSO, A. La situation des "réfugiés" em tunisie, une réponse bien trop imparfaite. Observatoire Pharos, 20 jun. 2019. Disponível em: https://www.observatoirepharos. $\mathrm{com} / \mathrm{pays} /$ tunisie/la-situation-des-refugies-en-tunisie-une-reponse-bien-tropimparfaite-fr/ Acesso em: 10 jan. 2020.

22. EL GUINDI, F. Veil: Modesty, Privacy and Resistance. Oxford/New York: Berg., 1999.

23. EL-MASRI, R.; GARWOOD, R.; HARVEY, C. Shifting Sands: Changing Gender Roles among Refugees in Lebanon. Joint Research Report, Sept. 2013. Disponível em: http://policy-practice.oxfam.org.uk/publications/shifting-sands-changing-gender-rolesamong-refugees-in-lebanon-300408. Acesso em: 10 jan. 2020.

24. FASSIN, D. La raison humanitaire: une histoire morale du temps présent. Hautes études, Paris, Éditions de l’EHESS (avec Le Seuil/Gallimard), 2010.

25. HAMID, S. C. (Des)integrando refugiados: os processos do reassentamento de palestinos no Brasil. 2012. 326 f. Tese (Doutorado em Antropologia Social) — Instituto de Ciências Sociais, Universidade de Brasília, Brasília, DF, 2012.

26. HARRELL-BOND, B. “Can Humanitarian Work With Refugees be Rumane?”, Human Rights Quarterly 24(1), p. 51-85, 2002.

27. JOSEPH, S. Intimate Selving in Arab Families. Gender, Self, and Identity. Syracuse: Syracuse University Press, 1999. 
28. JOSEPH, S. Brother/Sister Relationships: Connectivity, Love, and Power in the Reproduction of Patriarchy in Lebanon. American Ethnologist, v. 21, n. 1, p. 50-73, 1994.

29. KANDIYOTI, D. Women, Islam and the State. Basingstoke: Macmillan, 1991.

30. KELLER, L. S. Uprooting and Social Change: The Role of Refugees in Development. Manohar Book Service, New Delhi, 1975.

31. LIAMPUTTONG, P. Researching the Vulnerable: a Guide to Sensitive Research Methods. London: SAGE Publications, 2007.

32. LOKOT, M. "Blood doesn't become Water?" Syrian Social Relations during Displacement. Journal of Refugee Studies, p. 1-22, Dec. 2018.

33. MALKKI, L. Refugees and Exile: from "Refugee Studies" to the National Order of Things. Annual Review of Antropology, v. 24, p. 495-523, 1995.

34. MALKKI, L. Speechless Emissaries: Refugees, Humanitarianism, and Dehistoricization. Cultural Anthropology, v. 11, n. 3, p. 377-404, 1996.

35. MAHMOOD, S. Politics of Piety: The Islamic Revival and the Feminist Subject. New Jersey: Princeton University Press, 2005.

36. MAZUMDAR, S.; MAZUMDAR, S. Rethinking Public and Private Space: Religion and Women in Muslim Society. Journal of Architectural and Planning Research, v. 18, n. 4, p. 302-24, 2001.

37. MEIHY, R. A. Refúgios e diásporas. Identidade religiosa e memória coletiva entre refugiados do conflito sírio assentados em São Paulo. 2019. 148 f. Dissertação (Mestrado em Antropologia) - Universidade Federal Fluminense, Niterói, 2019.

38. NAVIA, A. F. Éxodos e refúgios: colombianos refugiados no Sul e Sudeste do Brasil. 2014. 405 f. Tese (Doutorado em Antropologia) - Museu Nacional, Universidade Federal do Rio de Janeiro, Rio de Janeiro, 2014.

39. PINTO, P. G. H. Syria. In: AMAR, P.; PRASHAD, V. (org.). Dispatches from the Arab Spring: Understanding the New Middle East. Minneapolis: University of Minnesota Press, 2013.

40. PINTO, P. G. H. The Shattered Nation: The Sectarianization of the Syrian Conflict. In: HASHEMI, N.; POSTEL, D. (org.) Sectarianization: Mapping the New Politics of the Middle East. London: Hurst \& Company, 2017. p. 123-42.

41. RABO, A. Gender, State and Civil Society in Jordan and Syria. In: HANN, C.; DUN, E. (org.). Civil Society: Challenging Western Models. London: Routledge Ltd, 1996. p. $155-77$.

42. RABO, A. Doing Family: Two Cases in Contemporary Syria. Hawwa, v. 6, n. 2, p. 129- 
153,2008

43. SA'AR, A. Lonely in Your Firm Grip: Women in Israeli-Palestinian Families. Journal of the Royal Anthropological Institute, v. 7, n. 4, p. 723-39, 2001.

44. SALAMANDRA, C. A new old Damascus: Authenticity and Distinction in Urban Syria. Bloomington: Indiana University Press, 2004.

45. SALAMANDRA, C. Chastity Capital: Hierarchy and Distinction in Damascus. In: KHALAF, S.; GAGNON, J. (org.). Sexuality in the Arab World. London: Saqi Books, 2006. p. 152-62.

46. SCHIOCCHET, Leonardo. Refugee Lives: Ritual and Belonging in Two Palestinian Refugee Camps in Lebanon. Boston/Massachusetts, USA: Boston University (BU), 2011.

47. SHARIF, H. Refugee-led Humanitarianism in Lebanon's Shatila Camp. Forced Migration Review, v. 57, p. 10-2, 2018.

48. SOUZA, M. A.; MANFRINATO, H. M. Refugees of the Syrian Conflict and the Struggle for Housing in Brazil. In: SCHIOCCHET, L.; MOKRE, M.; NÖLLE-KARIMINI, C. (org.). Agency and Tutelage in Forced Migration. Viena: ROR-n e OAW, 2020. p. $119-25$.

49. STEIN, B. N. The Refugee Experience: Defining the Parameters of a Field of Study. The International Migration Review, vol. 15, no. 1/2, pp. 320-330, 1981.

50. STEVENS, M. R. The Collapse of Social Net Workings among Syrian Refugees in Urban Jordan. Contemporary Levant, v. 1, n. 1, p. 51-63, 2016.

51. SZANTO, E. Sectarianism and the Syrian Uprising. Sulaimani Forum Journal, v. 3, n. p, 2013. Disponível em: https://www.academia.edu/2946944/Sectarianism_and_the_ Syrian_Uprising Acesso em: 01 jul. 2021

52. TURESS. L'organisation de la conference sur la Syrie exprime la solidarité avec le peuple syrien (R. Abdessalen). TURESS, 17 fev. 2012. Disponível em: http://www. turess.com/fr/tapfr/119234. Acesso em: 12 jan. 2020.

53. UNHCR. Woman Alone: Fight for Survival by Syria's Refugee Women. [S.l.: s.n.], 2014. Disponível em: https://www.unhcr.org/ar/53bb8d006.pdf. Acesso em: 20 mar. 2020.

54. URIARTE, P.; MONTEALEGRE, N. Al menos un puñado de gurises. Uma experiência de reasentamiento de niños sírios en Uruguay. Athenea Digital, v. 18, n. 1, p. 91-112, 2018.

55. WOMEN'S REFUGEE COMMISSION. Unpacking Gender: The Humanitarian Response to the Syrian Refugee Crisis in Jordan. [S.l.: s.n.], 2014. Disponível em: https://womensrefugeecommission.org/resources/gender-issues/985-unpacking-gender- 
the-humanitarian-response-to-the-syrian-refugee-crisis-in-jordan. Acesso em: 01 mar. 2020 .

56. WEDEEN, L. Ambiguities of Domination: Politics, Rhetoric, and Symbols in Contemporary Syria. Chicago/London: University of Chicago Press, 1999.

Mirian Alves de Souza

Doutora em Antropologia pelo Programa de Pós-graduação em Antropologia da Universidade Federal Fluminense. Professora do Departamento de Antropologia e do Programa de Pós Graduação em Justiça e Segurança da Universidade Federal Fluminense. Pesquisadora do Núcleo de Estudos do Oriente Médio, do Instituto de Estudos Comparados em Administração de Conflitos e do Refugee Outreach \& Research Network. ID ORCID: https://orcid.org/00000001-7153-9335. E-mail: mirianalves@id.uff.br. 